\title{
Varying the rate of intravenous cocaine infusion influences the temporal dynamics of both drug and dopamine concentrations in the striatum
}

\author{
Ellie-Anna Minogianis, ${ }^{1}$ Waqqas M. Shams, ${ }^{2}$ Omar S. Mabrouk, ${ }^{3}$ Jenny-Marie T. Wong, ${ }^{4}$ Wayne G. Brake, ${ }^{2}$ \\ Robert T. Kennedy, ${ }^{3,4}$ Patrick du Souich ${ }^{1}$ and Anne-Noël Samaha ${ }^{1,5}$ (iD \\ ${ }^{1}$ Department of Pharmacology and Physiology, Faculty of Medicine, Université de Montréal, C.P. 6128, Succursale Centre-ville, \\ Montreal, QC H3C 3J7, Canada \\ ${ }^{2}$ Department of Psychology, Center for Studies in Behavioral Neurobiology (CSBN), Concordia University, Montreal, QC, Canada \\ ${ }^{3}$ Department of Pharmacology, University of Michigan, Ann Arbor, MI, USA \\ ${ }^{4}$ Department of Chemistry, University of Michigan, Ann Arbor, MI, USA \\ ${ }^{5}$ Groupe de recherche sur le système nerveux central, Faculty of Medicine, Université de Montréal, Montreal, QC, Canada
}

Keywords: cocaine addiction, in vivo microdialysis, locomotor activity, male Wistar rats, pharmacokinetics

\begin{abstract}
The faster drugs of abuse reach the brain, the greater is the risk of addiction. Even small differences in the rate of drug delivery can influence outcome. Infusing cocaine intravenously over 5 vs. 90-100 s promotes sensitization to the psychomotor and incentive motivational effects of the drug and preferentially recruits mesocorticolimbic regions. It remains unclear whether these effects are due to differences in how fast and/or how much drug reaches the brain. Here, we predicted that varying the rate of intravenous cocaine infusion between 5 and $90 \mathrm{~s}$ produces different rates of rise of brain drug concentrations, while producing similar peak concentrations. Freely moving male Wistar rats received acute intravenous cocaine infusions ( $2.0 \mathrm{mg} / \mathrm{kg} / \mathrm{infusion})$ over 5 , 45 and $90 \mathrm{~s}$. We measured cocaine concentrations in the dorsal striatum using rapid-sampling microdialysis (1 sample/min) and high-performance liquid chromatography-tandem mass spectrometry. We also measured extracellular concentrations of dopamine and other neurochemicals. Regardless of infusion rate, acute cocaine did not change concentrations of non-dopaminergic neurochemicals. Infusion rate did not significantly influence peak concentrations of cocaine or dopamine, but concentrations increased faster following 5-s infusions. We also assessed psychomotor activity as a function of cocaine infusion rate. Infusion rate did not significantly influence total locomotion, but locomotion increased earlier following 5-s infusions. Thus, small differences in the rate of cocaine delivery influence both the rate of rise of drug and dopamine concentrations, and psychomotor activity. A faster rate of rise of drug and dopamine concentrations might be an important issue in making rapidly delivered cocaine more addictive.
\end{abstract}

\section{Introduction}

The rate of drug delivery to the brain is important in determining the risk of developing addiction. For instance, smoking cocaine or injecting the drug intravenously is associated with a greater vulnerability to addiction than intranasal use (Gossop et al., 1994; Hatsukami \& Fischman, 1996). After smoking or intravenous (i.v.) infusion, plasma cocaine concentrations rise more rapidly and reach higher peaks than after intranasal administration (Javaid et al., 1978; Jeffcoat et al., 1989; Jones, 1990). Such pharmacokinetic differences

Correspondence: Anne-Noël Samaha, ${ }^{1}$ Department of Pharmacology and Physiology, as above. E-mail: Anna.samaha@umontreal.ca

Received 8 December 2017, revised 26 March 2018, accepted 27 March 2018

Edited by Michel Barrot. Reviewed by Vedran Lovic, University of Calgary, Canada; and Pascal Romieu, CNRS, France.

All peer review communications can be found with the online version of the article. are important in determining outcome. For instance, different pharmacokinetic profiles are one reason why the same drug can lead to addiction when taken by one route (nicotine inhaled from tobacco smoke) but can treat addiction when taken by another (nicotine administered orally from a gum or through the skin from a patch, Henningfield \& Keenan, 1993).

Varying the rate of drug delivery to the brain influences the psychological and behavioural effects of drugs. In humans, cocaine (Resnick et al., 1977) and heroin (Comer et al., 1999) evoke more immediate and stronger pleasurable effects when administered i.v. rather than intranasally. Similarly, increasing the rate of i.v. cocaine (Fischman \& Schuster, 1984; Abreu et al., 2001) or morphine (Marsch et al., 2001) infusion produces greater self-reports of euphoria. Early studies in laboratory animals show that relatively large variations in the rate of i.v. drug administration (i.e., injecting a dose between 5-600 s) influence cocaine self-administration behaviour (Balster \& Schuster, 1973; Woolverton \& Wang, 2004). More 
recent experiments have explored the effects of varying the rate of i.v. infusion over a smaller range of time (5-100 s). Doing so is important for three main reasons. First, experienced i.v. cocaine users report that they inject the drug rapidly and over a narrow range (3-10 s, Zernig et al., 2003). Second, the time difference in the onset of subjective drug effects in i.v. vs. intranasal cocaine users is also narrow (2-9 s, Zernig et al., 2003 and 30-120 s, Jones, 1984; Weiss et al., 1993, respectively). Finally, injecting cocaine i.v. over 2 vs. $60 \mathrm{~s}$ influences the magnitude of subjective cocaine effects in humans (Abreu et al., 2001). Such small differences in the rate of drug delivery can have large effects on behaviour in laboratory rats. For instance, injecting cocaine or nicotine i.v. over 5 vs. $90-100 \mathrm{~s}$ promotes sensitization to the psychomotor (Samaha et al., 2002, 2004; Samaha \& Robinson, 2005; Allain et al., 2017) and incentive motivational effects of these drugs (Liu et al., 2005; Minogianis et al., 2013; Bouayad-Gervais et al., 2014; Allain et al., 2017). Rats that self-administer i.v. cocaine injections delivered over 5 vs. $90 \mathrm{~s}$ also take more drug (Wakabayashi et al., 2010; Minogianis et al., 2013; Bouayad-Gervais et al., 2014), and are more susceptible to relapse following extended abstinence (Wakabayashi et al., 2010).

Variation in the rate of drug delivery influences behaviour presumably because it changes the neurobiological impact of drugs. Studies in rats show that increasing the rate of cocaine delivery to the brain enhances cellular activity in mesocorticolimbic areas (reviewed in Samaha \& Robinson, 2005). A first study showed that compared to intraperitoneal cocaine, i.v. cocaine enhances glucose utilization in corticolimbic regions (Porrino, 1993). More recent work shows that injecting cocaine i.v. over 5 vs. 90-100 s increases drug-induced immediate early gene expression (Samaha et al., 2004), heat-producing metabolic activity (Brown \& Kiyatkin, 2005), and regulation of the growth factor, brain-derived neurotrophic factor and its receptor TrkB (Bouayad-Gervais et al., 2014). Chronic intake of i.v. infusions of cocaine delivered over $5 \mathrm{~s}$ but not over $90 \mathrm{~s}$ also increases the function of metabotropic group II receptors in the prelimbic cortex and nucleus accumbens (Allain et al., 2017).

Thus, small differences in the rate of i.v. cocaine delivery can predict outcome but is this due to how fast cocaine enters the brain, peak concentration achieved, or both? This question remains unanswered because brain concentrations of cocaine have been modelled (Samaha et al., 2002; Allain et al., 2017), but not actually measured as a function of the rate of i.v. drug delivery. It is possible that varying the rate of i.v. drug infusion, even over a small range, produces differences in achieved concentration, and this could contribute to the effects seen on brain and behaviour. However, beyond achieved dose, temporal pharmacokinetic variables such as how fast drug levels rise can determine behavioural and neurobiological effects relevant to addiction (Allain et al., 2015, 2017). The brain is sensitive to the temporal pattern of cellular stimulation. For instance, in a context outside of drugs of abuse, different temporal patterns of electrical stimulation are differentially effective in producing longterm potentiation (Larson \& Lynch, 1986) and dopamine-evoked synaptic plasticity (Wieland et al., 2015).

Here, we hypothesized that varying the rate of i.v. cocaine delivery between 5 and $90 \mathrm{~s}$ produces differences in the rate of rise of striatal cocaine and dopamine concentrations, without producing large effects on peak concentrations. We make this prediction first because it is supported by pharmacokinetic modelling (Samaha et al., 2002; Allain et al., 2017; where the pharmacokinetic model was based on Pan et al., 1991). Second, dopamine and cocaine concentrations are tightly correlated in the brain (Nicolaysen et al., 1988; Shou et al., 2006), and injecting cocaine i.v. over 5 vs. $100 \mathrm{~s}$ produces differences in the rate of rise of extracellular dopamine concentrations in the striatum, without affecting peak concentrations (Ferrario et al., 2008 but see Samaha et al., 2004, where brief differences in the half-life of electrically stimulated extracellular dopamine were observed). To test our hypothesis, we injected freely moving rats with i.v. infusions of cocaine delivered over 5, 45 and $90 \mathrm{~s}$, and we used rapid-sampling (1 sample/min) microdialysis coupled with high performance liquid chromatography-tandem mass spectrometry (HPLC-MS/MS) to simultaneously measure cocaine and dopamine concentrations in the dorsal striatum (DS). We measured dopamine concentrations because cocaine-induced increases in dopamine overflow regulate the incentive motivational effects of the drug. The microdialysis samples were also used to determine cocaine effects on 20 other neurochemicals in the striatum. As an additional functional measure, we assessed the psychomotor response to acute cocaine infused over 5,45 and $90 \mathrm{~s}$, in a separate cohort of rats. Based on prior work, we predicted that varying the rate of cocaine delivery over this range would not influence the magnitude of the locomotor response (Samaha et al., 2002), but that rate could influence the time course of cocaine-induced locomotion.

\section{Materials and methods}

\section{Animals and housing}

Twenty male Wistar rats (seven for microdialysis and thirteen for cocaine-induced psychomotor activity; Charles River Laboratories, St-Constant, QC, Canada) weighing between 225 and $300 \mathrm{~g}$ upon arrival were housed individually in a climate-controlled colony room maintained on a reverse $12 \mathrm{~h} / 12 \mathrm{~h}$ light/dark cycle (lights off at 8:30-9:00 am). Experiments were conducted during the dark phase of the rats' circadian cycle. Food and water were available ad libitum. The animal care committees of the Université de Montréal (CDEA 14-149 and 17-095) and of Concordia University approved all procedures involving animals. These procedures complied with guidelines of the Canadian Council on Animal Care.

\section{Surgery}

Following 1-4 weeks of acclimatization to the vivarium, a custommade, indwelling catheter was implanted into the jugular vein of rats anaesthetized with isoflurane (CDMV, Saint-Hyacinthe, QC, Canada). The other end of the catheter was set to exit between the scapulae. Animals to be used for in vivo microdialysis were then placed in a stereotaxic apparatus and a cannula (21-gauge; HRS Scientific, Montreal, QC, Canada) was implanted into the DS of one hemisphere (counterbalanced across animals; coordinates relative to Bregma; anteroposterior, $+1.6 \mathrm{~mm}$, mediolateral, $\pm 2.5 \mathrm{~mm}$, and dorsoventral, $-3.0 \mathrm{~mm}$ ). Cannulae were anchored to the skull with jeweller's screws, secured in place with dental cement and sealed with obturators (22-gauge; HRS Scientific). We targeted the DS because it is rich in dopamine transporters and it mediates the expression of addiction-related behaviours (Everitt \& Robbins, 2005). At the time of surgery, rats received a subcutaneous injection of $5 \mathrm{mg} / \mathrm{kg}$ Carprofen (Rimadyl; $50 \mathrm{mg} / \mathrm{mL}$; CDMV) and an intramuscular injection of $0.02 \mathrm{~mL}$ of a penicillin $\mathrm{G}$ procaine solution (Procillin; $300000 \mathrm{IU} / \mathrm{mL}$; CDMV). Intravenous catheters were flushed on alternate days with either $0.1 \mathrm{~mL}$ physiological saline or a solution containing $0.2 \mathrm{mg} / \mathrm{mL}$ Heparin (Sigma-Aldrich, Oakville, ON, Canada) and $2 \mathrm{mg} / \mathrm{mL}$ of the antibiotic Baytril (CDMV). Rats recovered in their home cages for 7 days prior to further manipulation. 


\section{Determination of microdialysis probe delay time in vitro}

A first goal was to measure the delay time between placement of our microdialysis probes into a cocaine solution, and detection of the drug in a collected sample. This is important, as it provides a measure of the inevitable delay time that a sample needs to travel from the microdialysis probe, through the tubing set-up and finally into the sample collection vials. Two custom-made microdialysis probes (described below) were perfused at $2 \mu \mathrm{L} / \mathrm{min}$ with artificial cerebrospinal fluid (aCSF) containing $145 \mathrm{~mm} \mathrm{NaCl}, 2.68 \mathrm{~mm} \mathrm{KCl}$, $1.40 \mathrm{~mm} \mathrm{CaCl} 2 * 2 \mathrm{H}_{2} \mathrm{O}, 1.01 \mathrm{~mm} \mathrm{MgSO}{ }_{4} * 7 \mathrm{H}_{2} \mathrm{O}, 1.55 \mathrm{~mm} \mathrm{Na}_{2} \mathrm{HPO}_{4}$, $0.45 \mathrm{~mm} \mathrm{NaH}{ }_{2} \mathrm{PO}_{4} * \mathrm{H}_{2} \mathrm{O}$ in HPLC-grade water $(\mathrm{pH}=7.4$; chemicals from Fisher Scientific, Saint-Laurent, QC, Canada; water from Sigma Aldrich, Oakville, ON, Canada). Probes were first placed into a beaker containing a stirred solution of aCSF and ascorbic acid $(0.25 \mathrm{~mm})$ at room temperature. After $20 \mathrm{~min}, 10$ samples were collected at 1-min intervals. Probes were then transferred to a second beaker containing aCSF + ascorbic acid solution and $1 \mu \mathrm{m}$ cocaine, from which 26 samples were taken. Finally, the probes were returned to the aCSF + ascorbic acid solution and 16 additional samples were collected. Samples were collected in $300-\mu \mathrm{L}$ microcentrifuge vials (VWR, Montreal, QC, Canada), and immediately placed in dry ice and stored at $-80^{\circ} \mathrm{C}$ until analysis by HPLC-MS/ MS.

\section{In vivo microdialysis probes}

In vivo microdialysis was conducted in four custom-made hexagonal chambers $(42 \times 39 \times 33.5 \mathrm{~cm})$ each placed within a larger soundand light-attenuating cabinet. Microdialysis probes were custommade. They consisted of a $1 \mathrm{~cm}$ length of semi-permeable dialysis membrane $(200 \mu \mathrm{m} \mathrm{ID,} 216 \mu \mathrm{m}$ OD, with a molecular weight cutoff of $13 \mathrm{kDa}$; VWR) that extended $4 \mathrm{~mm}$ below the tip of the guide cannula. The membrane was inserted into a $20-\mathrm{mm}$ length of 26G stainless steel tubing. The outer end of the membrane was occluded with super glue to create a closed system for dialysate flow. The stainless-steel shaft was inserted into one end of polyethylene (PE) 20 tubing (0.38 mm ID, $1.09 \mathrm{~mm}$ OD; $65 \mathrm{~cm}$ long; Scientific Commodities Inc., Lake Havasu City, AZ, USA), while the other end was connected to a dual-channel liquid swivel (Lomir, Notre-Dame-de-l'Ile-Perrot, QC, Canada). The swivel was in turn connected to a syringe pump (Harvard Apparatus, Saint-Laurent, QC, Canada) with PE-20 tubing. Small-diameter fused silica tubing (41 $\mu \mathrm{m}$ ID, $110 \mu \mathrm{m}$ OD; $2 \mathrm{~cm}$ long; HRS Scientific) extended into the probe $0.5 \mathrm{~mm}$ from the glued tip of the semi-permeable membrane. The other end of the fused silica was glued to PE-1 tubing $(0.127 \mathrm{~mm} \mathrm{ID}, 0.254 \mathrm{~mm}$ OD; $60 \mathrm{~cm}$ long) that extended out of the PE-20 tubing, serving as an outlet for the probe. The microdialysis probe was secured to the cannula with a stainless-steel collar. The relative recovery rates from the microdialysis probes were $10 \%$ for cocaine and $8-15 \%$ for dopamine.

\section{In vivo microdialysis experiment}

Figure 1A illustrates the sequence of experimental events. Following recovery from surgery, microdialysis rats were placed in the test chambers for two, 3.5-h habituation sessions (one/day). Their catheters were tethered to the i.v. drug infusion line and their cannulae were tethered to the steel spring casing used to protect the microdialysis tubing during sampling. During each habituation session, each rat received $78 \mu \mathrm{L}$ of saline i.v. over 5,45 and $90 \mathrm{~s}$, with one infusion given every $90 \mathrm{~min}$ in counter-balanced order. We injected a volume of $78 \mu \mathrm{L}$ because for cocaine injections, we would inject $34 \mu \mathrm{L}$ of saline to account for average catheter volume $+10 \mu \mathrm{L}$ cocaine solution $+34 \mu \mathrm{L}$ of saline to ensure that none of the cocaine remains in the catheter. Catheter patency was verified on the second habituation day by i.v. infusion of the short-acting barbiturate, sodium thiopental $(20 \mathrm{mg} / \mathrm{mL}$ in sterile water, $0.1-0.2 \mathrm{~mL} / \mathrm{rat}$; CDMV). All rats became ataxic within $5 \mathrm{~s}$ of the infusion, confirming catheter patency. In rats, sodium thiopental has a $T_{1 / 2}$ of $\sim 4-5 \mathrm{~h}$ (Shideman et al., 1953), thus we do not expect it to influence microdialysis measurements performed on the next day. On the following day, rats were placed in the test chambers and dialysis probes were lowered into the striatum for a 5-h habituation period. During this period, aCSF was perfused through the microdialysis probe at a rate of $2.0 \mu \mathrm{L} / \mathrm{min}$. Rats were awake and freely moving during the experiment. Three hours and $50 \mathrm{~min}$ into the habituation period, animals were tethered to the cocaine infusion line. It contained $10 \mu \mathrm{L}$ of cocaine solution (Medisca Pharmaceutique Inc, St-Laurent, QC, Canada; $2 \mathrm{mg} / \mathrm{kg} /$ infusion in $0.9 \%$ physiological saline) separated from additional saline by a small air bubble. The other end of the line was attached to a 3 c.c. BD syringe placed on a syringe pump. A $2 \mathrm{mg} / \mathrm{kg}$ dose of cocaine is similar to doses used in prior studies that have measured cocaine or dopamine concentrations in the striatum using in vivo microdialysis (Hurd et al., 1988; Hurd \& Ungerstedt, 1989; Ferrario et al., 2008). This dose also evokes robust immediate early gene expression in the DS (Samaha et al., 2004).

Over the last $10 \mathrm{~min}$ of the 5 -h habituation period, 10 baseline dialysate samples were collected, at 1-min intervals and at a flow rate of $2.0 \mu \mathrm{L} / \mathrm{min}$, yielding $2.0 \mu \mathrm{L} / \mathrm{sample}$. Next, each animal received the first of three i.v. cocaine infusions $(2.0 \mathrm{mg} / \mathrm{kg} / 10 \mu \mathrm{L} /$ infusion), delivered over 5, 45 and $90 \mathrm{~s}$, injected $90 \mathrm{~min}$ apart, in counter-balanced order. Cocaine infusions were spaced $90 \mathrm{~min}$ apart because this is 3-4 times longer than cocaine's $\mathrm{T}_{1 / 2}$ in rat brain (Nayak et al., 1976; Hurd et al., 1988). Thus, the 90-min inter-infusion interval reduces the possibility of carry-over effects between infusions (see also Hurd et al., 1988). Following each cocaine infusion, 15 samples were collected, at 1-min intervals. Five 1-min baseline samples were also collected prior to the 2 nd and 3rd cocaine infusions. Samples were collected in a $300-\mu \mathrm{L}$ polypropylene microsampling vial placed on the end of the outlet line. Samples were immediately placed in dry ice and stored at $-80^{\circ} \mathrm{C}$ until processing. At the end of sampling, each microdialysis probe was visually inspected for leaks or breakage. None were detected.

\section{High performance liquid chromatography-tandem mass spectrometry (HPLC-MS/MS)}

\section{Small molecule neurochemical analysis using a triple quadrupole (QQQ) $M S$}

All chemicals were from Sigma Aldrich (St. Louis, MO, USA) unless noted otherwise. Water and acetonitrile for mobile phases were Burdick \& Jackson HPLC grade (VWR, Radnor, PA, USA). Artificial CSF consisted of $145 \mathrm{~mm} \mathrm{NaCl}, 2.68 \mathrm{~mm} \mathrm{KCl}, 1.40 \mathrm{~mm} \mathrm{CaCl}_{2}$, $1.01 \mathrm{~mm} \mathrm{MgSO}_{4}, 1.55 \mathrm{~mm} \mathrm{Na} \mathrm{HPO}_{4}$, and $0.45 \mathrm{~mm} \mathrm{NaH} \mathrm{PO}_{4}$, adjusted $\mathrm{pH}$ to 7.4 with $\mathrm{NaOH}$. Cocaine standards (Mallinckrodt Inc., St. Louis, MO, USA) were spiked into a standard mixture for a sixpoint calibration curve. A modified LC-MS method (Song et al., 2012; Wong et al., 2016) was used to quantify concentrations of extracellular cocaine and dopamine, as well as acetylcholine, adenosine, aspartate, 3,4-dihydroxyphenylacetic acid, $\gamma$-aminobutaric acid, 


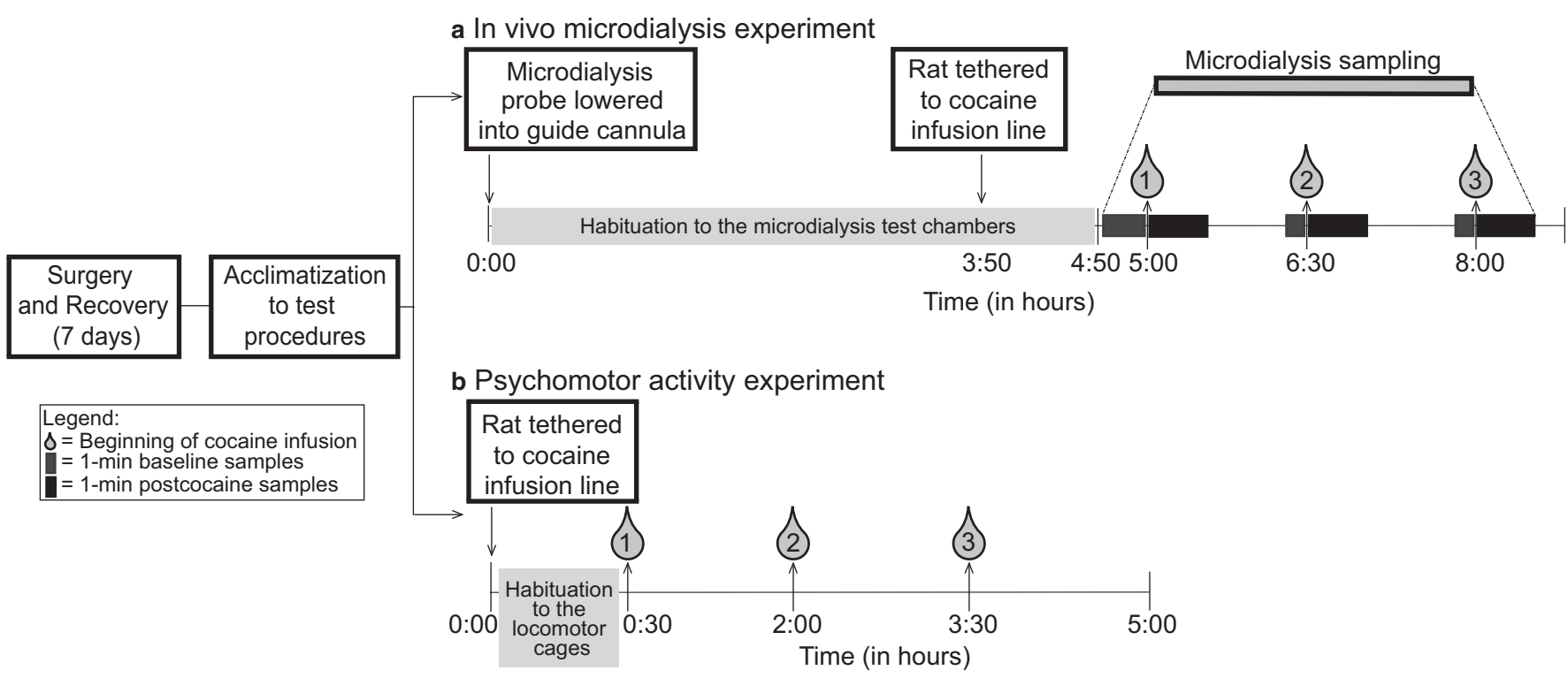

FIG. 1. The sequence of experimental events. Panel (a) illustrates the timeline of experimental events for the in vivo microdialysis study. Rats were implanted with a unilateral cannula into the dorsal striatum (DS) and a catheter into the jugular vein. Following recovery, the rats were habituated to the in vivo microdialysis apparatus and to the i.v. infusion procedure on two daily sessions. On the following test day, microdialysis probes were inserted into the DS and i.v. catheters were tethered to the cocaine infusion set up. Each rat received an i.v. infusion of $2 \mathrm{mg} / \mathrm{kg}$ cocaine, delivered over 5 , 45 or $90 \mathrm{~s}$, in counterbalanced order, with infusions administered $90 \mathrm{~min}$ apart. Dialysate samples were collected every minute for 5-10 min before each infusion and for 15 min thereafter. Panel (b) shows the sequence of experimental events for the psychomotor activity study. Rats were implanted with an intrajugular catheter and allowed to recover for 7 days. Rats were then habituated to the psychomotor activity cages and i.v. infusion lines on two daily sessions. On the following test day, rats were tethered to the cocaine infusion lines and locomotor activity was measured. Each rat received i.v. cocaine ( $2.0 \mathrm{mg} / \mathrm{kg} / \mathrm{infusion}) \mathrm{delivered} \mathrm{over} 5$, 45 and $90 \mathrm{~s}$, in counterbalanced order, with infusions administered 90 min apart.

glutamate, glutamine, glucose, glycine, histamine, 5-hydroxyindoleacetic acid, homovanillic acid, 3-methoxytyramine, norepinephrine, normetanephrine, phenylalanine, serine, serotonin, taurine, and tyrosine. Samples were thawed and derivatized with $1.5 \mu \mathrm{L}$ sodium carbonate, $100 \mathrm{~mm}$; $1.5 \mu \mathrm{L} \mathrm{BzCl}, 2 \%$ (v/v) $\mathrm{BzCl}$ in acetonitrile; $1.5 \mu \mathrm{L}$ isotopically labelled internal standard mixture diluted in $50 \%(\mathrm{v} / \mathrm{v})$ acetonitrile containing $1 \%(\mathrm{v} / \mathrm{v})$ sulphuric acid, and spiked with deuterated acetylcholine and choline (C/D/N isotopes, Pointe-Claire, QC, Canada) to a final concentration of 20 nM. Derivatized samples were analysed using Thermo Scientific Accela UHPLC system interfaced to a Thermo Scientific TSQ Quantum Ultra triple quadrupole mass spectrometer fitted with a HESI II ESI probe, operating in multiple reaction monitoring. Five- $\mu \mathrm{L}$ samples were injected onto a Phenomenex core-shell biphenyl Kinetex HPLC column $(1.7 \mu \mathrm{m}$ particles, $2.1 \mathrm{~mm} \times 100 \mathrm{~mm}$ ). Mobile phase A was $10 \mathrm{~mm}$ ammonium formate with $0.15 \%$ formic acid, and mobile phase B was acetonitrile. Mass transitions for these derivatized analytes were reported in Wong et al. (2016). Cocaine was detected in its native form with a MS/MS transition of $304 \rightarrow 182 \mathrm{~m} / \mathrm{z}$. The mobile phase was delivered through an elution gradient at $450 \mu \mathrm{L} / \mathrm{min}$ as follows: initial, $0 \% \mathrm{~B}$; $0.01 \mathrm{~min}, 19 \% \mathrm{~B} ; 1 \mathrm{~min}, 26 \% \mathrm{~B} ; 1.5 \mathrm{~min}, 75 \% \mathrm{~B} ; 2.5 \mathrm{~min}, 100 \% \mathrm{~B}$; $3 \mathrm{~min}, 100 \% \mathrm{~B} ; 3.1 \mathrm{~min}, 5 \% \mathrm{~B}$; and $3.5 \mathrm{~min}, 5 \% \mathrm{~B}$. THERMO XCALIBUR QUANBROWSER (Thermo Fisher Scientific) software automatically processed and integrated peaks. Each peak was visually inspected to ensure proper integration. The limits of detection for cocaine and dopamine after derivatization were 0.291 and $0.086 \mathrm{~nm}$, respectively. Limits of detection for the other analytes were $0.045-141 \mathrm{~nm}$.

\section{Histology}

Following sampling, animals were anaesthetized with isoflurane and decapitated. Brains were then extracted, frozen and stored at $-80^{\circ} \mathrm{C}$.
The neuroanatomical location of the probes was estimated on $20-\mu \mathrm{m}$ thick coronal brain sections, according to the rat brain atlas of Paxinos \& Watson (1986).

\section{Psychomotor activity experiment}

Figure 1B shows the sequence of experimental events. Locomotor activity was assessed in four chambers $(31.8 \times 25.4 \times 26.7 \mathrm{~cm}$; Med Associates, St-Albans, VT, USA), each containing four infrared photocells aligned horizontally at the bottom of each cage. The chambers were run by a computer using Med Associates Med-PC version IV software (Med Associates). Following recovery from surgery, rats were placed in the test chambers for two, 2-h habituation sessions (one/day). Their catheters were tethered to the i.v. infusion line and a steel spring casing used to protect the line during testing. In the first habituation session, no i.v. infusion was given. During the second habituation session, rats received saline i.v. over 5,45 or $90 \mathrm{~s}, 30 \mathrm{~min}$ into the session. Following the end of this second habituation session, catheter patency was verified by i.v. infusion of Propofol (10 mg/mL; $0.1 \mathrm{~mL} / \mathrm{rat}$; CDMV), a short-acting anaesthetic $\left(\mathrm{T}_{1 / 2} \sim 27 \mathrm{~min}\right.$ in Wistar rats; Dutta et al., 1997). Sodium thiopental was not used in this 2nd experiment because it was no longer available from the manufacturer. All rats became ataxic within $5 \mathrm{~s}$ of the Propofol infusion, confirming catheter patency. On the next day, animals were placed in the test chambers and tethered to an infusion line containing the cocaine solution $(2.0 \mathrm{mg} / \mathrm{kg}$ in $10 \mu \mathrm{L})$. The other end of the line was attached to a 1 c.c. BD syringe and placed on a microsyringe pump (HAVARD PHD, 2000; HARVARD Apparatus). Following a 30-min habituation period, each animal received the first of three experimenter-administered i.v. cocaine infusions delivered over 5, 45 or $90 \mathrm{~s}$, injected $90 \mathrm{~min}$ apart and in counterbalanced order. The test session lasted five hours, and locomotor 
activity was recorded as photocell beam breaks, computed over 10-s intervals. At the end of the study, catheter patency was verified once again with Propofol and animals were immediately euthanized by decapitation while still under anaesthesia. One rat did not become ataxic and was eliminated from the study.

\section{Statistical analysis}

Data were analysed with PRISM 7 software (GraphPad Software Inc., La Jolla, CA, USA). Changes in cocaine concentration as a function of time during the in vitro assay were analysed using one-way analysis of variance (ANOVA). Repeated measures two-way ANOvA was used to analyse the effects of cocaine infusion rate on average extracellular concentrations of cocaine and dopamine over time, and on locomotor activity over time ('Infusion Rate' and 'Time' as withinsubjects variables). Repeated measures one-way ANOvA, followed by Tukey's multiple comparison tests or two-tailed paired $t$-tests, were used to analyse the effects of cocaine infusion rate on cocaine and dopamine $C_{\max }$ (the highest value for each analyte obtained from each rat after cocaine, averaged by infusion rate), $T_{\max }$ (time to reach $C_{\max }$ in each rat, averaged by infusion rate), and time to first significant increase (the first value $>2$ standard deviations above baseline in each rat, averaged by infusion rate). One-way ANOva was also used to assess the effects of cocaine infusion rate on both total locomotor activity (from minute ' 0 ' to minute ' 30 ') and locomotor activity within the first minute after injection. Linear regression was used for the correlations and Fisher's r-to-z transformation was then used to compare correlation coefficients $(r)$. Effects were considered statistically significant when $P<0.05$.

\section{Results}

\section{Determination of microdialysis probe delay time in vitro}

Figure 2 shows cocaine concentrations at 1-min intervals when microdialysis probes were placed in an aCSF/ascorbic acid solution, then in an aCSF/ascorbic acid/1 $\mu \mathrm{M}$ cocaine solution, and back again. Of note, apparent cocaine concentrations do not start at or return to ' 0 ' when the probes are placed in the aCSF/ascorbic acid solution, before and after probe immersion in the cocaine solution. This background signal is likely produced by a contaminant with a similar mass transition to cocaine. We overcame this issue by taking the background contaminant signal into account when assigning the lower limit of quantification (LLOQ) of the LC-MS assay. This LLOQ was estimated as being $3 \times$ greater than the signal generated in aCSF/ascorbic acid alone, or $23 \mathrm{~nm}$. The baseline values in Fig. 2 are all below $23 \mathrm{~nm}$ and thus these values can be considered to be a background signal. It is only when the dialysis probe is placed in the cocaine-containing solution that cocaine concentrations rise above the LLOQ. Once the microdialysis probes were placed into the cocaine solution, cocaine concentrations increased significantly from baseline levels (One-way ANOva on minutes -10 to 26; $\left.F_{35,36}=26.08 ; \quad P<0.0001\right)$. Cocaine concentrations began to increase 5-6 $\mathrm{min}$ after probe immersion into the cocaine solution, and reached near-maximum concentrations 1-2 min later. Thus, the delay time between the microdialysis probe and the collection vial is 5-6 min, and after this delay, near peak concentrations of cocaine were detected within 1-2 min. When the microdialysis probes were placed back into the solution that did not contain cocaine, drug concentrations significantly decreased (One-way ANOva on minutes 0 to 42; $\left.F_{42,43}=17.51 ; P<0.0001\right)$. Cocaine concentrations began to decrease 5-6 min after removal of the probes from the cocaine solution, and they returned to baseline levels 1-2 min later. Thus, there was a 5-6-min delay time to detect the presence and then absence of cocaine in a solution. This delay is the time it takes for aCSF to be transported across the microdialysis probe membrane, through the probe outlet tubing and into the collection vial. Residual cocaine is also removed from the microdialysis probes within $2 \mathrm{~min}$ after this delay time. Based on these findings, the curves illustrating brain cocaine and dopamine concentrations in vivo (Fig. 3) were corrected for a 5-min delay time.

\section{Varying the rate of i.v. cocaine delivery between 5 and $90 \mathrm{~s}$ significantly influences striatal cocaine and dopamine $\mathrm{T}_{\max }$, but not $\mathrm{C}_{\max }$}

In all seven rats, the unilateral microdialysis probe was located in the DS between 2.2 and $1.2 \mathrm{~mm}$ anterior to Bregma (Fig. 3a). Some probe tips extended slightly into the nucleus accumbens core. However, there would be little to no sampling from the probe tips as tips were occluded with super glue to create a closed system for dialysate flow. All animals received all three intravenous cocaine infusions administered over 5, 45 and $90 \mathrm{~s}$, in counter-balanced order. Baseline levels of cocaine and dopamine during the 5 min prior to each infusion were comparable (Cocaine: $F_{2,18}=1.42, P=0.27$; Dopamine: $F_{2,18}=0.15, P=0.86$; data not shown). Thus, cocaine and dopamine concentrations returned to pre-cocaine baseline levels before each infusion, and there were no significant carry-over effects from one infusion to the next. At all rates, i.v. cocaine administration increased extracellular concentrations of both cocaine and dopamine above baseline (Fig. $3 \mathrm{~b}$ and c, respectively). The rate of i.v. cocaine infusion significantly influenced cocaine and dopamine concentrations over time (Infusion rate $\times$ Time interaction effect; Fig. $3 b, F_{36,216}=4.38$; Fig. $3 c, F_{36,216}=3.56$; all $P$ 's $<0.0001$ ). There was no significant effect of the rate of i.v. cocaine infusion on peak concentrations ( $C_{\max }$ values) of cocaine (Fig. $4 \mathrm{a}$;

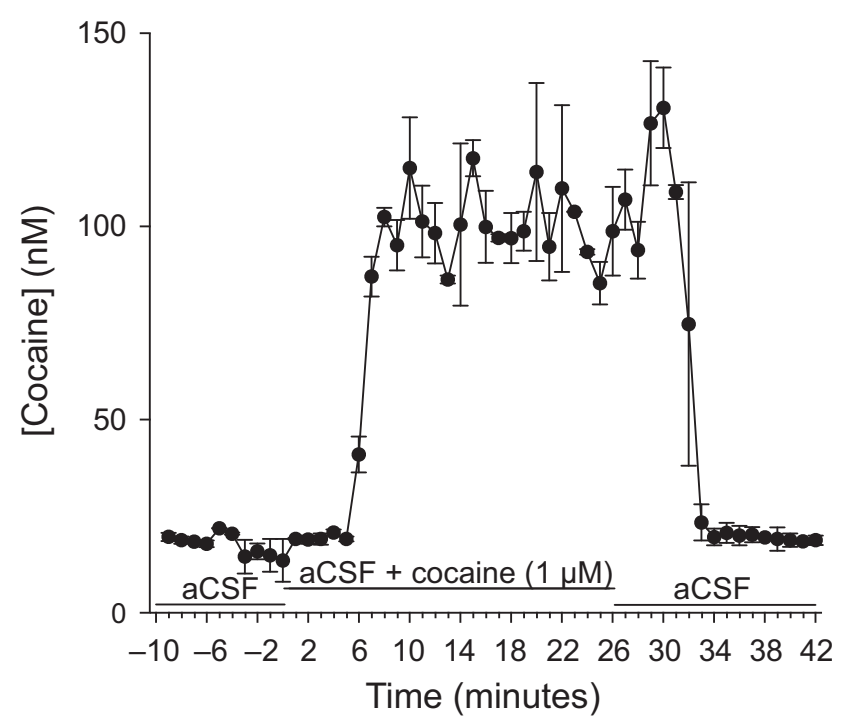

FIG. 2. Cocaine concentrations were detected when microdialysis probes were placed into a solution containing $1 \mu \mathrm{M}$ cocaine. Two probes were transferred each from a solution containing artificial cerebrospinal fluid (aCSF/ ascorbic acid to a solution containing aCSF/ascorbic acid/cocaine (1 $\mu \mathrm{M})$, and back again. All solutions were stirred and tested at room temperature. The data shown are averages $( \pm$ SEM) from two independent tests carried out with two different probes. Samples were collected at 1-min intervals, at a flow rate of $2 \mu \mathrm{L} / \mathrm{min}$, and analysed by HPLC-MS/MS. $\mathrm{n}=2 . \mu \mathrm{M}$, micromoles/litre; nм, nanomoles/litre. 

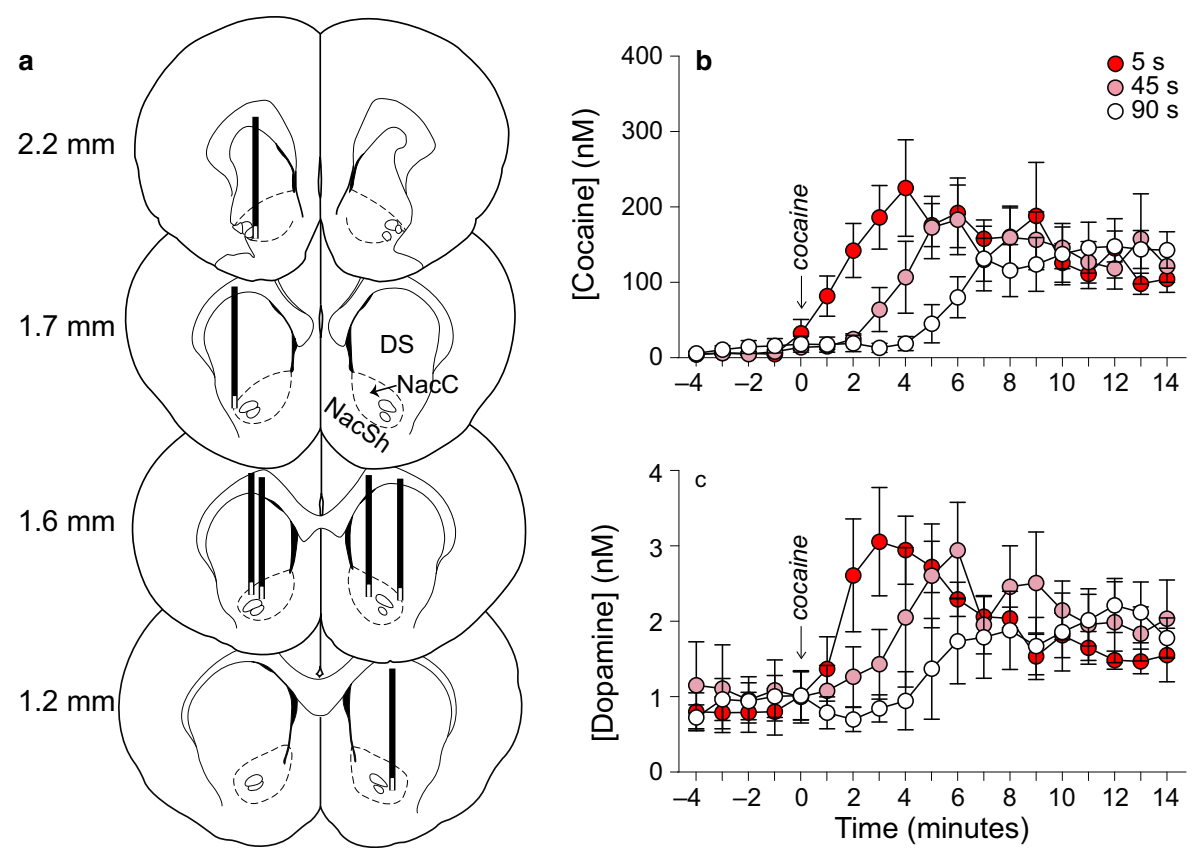

FIG. 3. Varying the rate of i.v. infusion between 5 and $90 \mathrm{~s}$ influences the temporal kinetics of extracellular cocaine and dopamine concentrations in the dorsal striatum. The location of microdialysis probes in the striatum is shown in panel (a). The distance in millimetres (mm) from Bregma is given for each coronal rat brain section. The white boxes at the tips of each probe indicate the segment where glue was applied, and where no exchange is possible. Panels (b) and (c) show striatal cocaine and dopamine concentrations over time, respectively, as a function of i.v. drug infusion rate. All values are mean \pm SEM. $n=7$ rats/infusion rate. DS, Dorsal Striatum, $N a c C$, Nucleus Accumbens Core, $N A c S h$, Nucleus Accumbens Shell, nm, nanomoles/litre. s, seconds.

$F_{1.61,9.67}=1.71, P=0.23 ; 5$ s: $267.82 \pm 52.11 ; 45$ s: $223.69 \pm$ 41.19; $90 \mathrm{~s}: 185.09 \pm 27.18 \mathrm{~nm}$ ) or dopamine (Fig. $4 \mathrm{~b} F_{1.41,8.44}=$ $0.87, \quad P=0.42 ; \quad 5 \mathrm{~s}: \quad 3.50 \pm 0.49, \quad 45 \mathrm{~s}: 3.79 \pm 0.82 ; \quad 90 \mathrm{~s}:$ $3.06 \pm 0.53 \mathrm{~nm})$. However, as hypothesized, peak concentrations of cocaine (Fig. 4c; $F_{1.5,9}=16.23, P=0.0016 ; 5-45 \mathrm{~s}<90 \mathrm{~s} ; 5 \mathrm{~s}$ : $4.33 \pm 0.86 ; 45 \mathrm{~s}: 6.86 \pm 1.28$; $90 \mathrm{~s}: 11.71 \pm 0.47 \mathrm{~min})$ and dopamine (Fig. 4d; $\quad F_{1.53,9.17}=7.34, \quad P=0.02 ; \quad 5<90 \mathrm{~s} ; \quad 5 \mathrm{~s}$ : $4.33 \pm 0.42 ; \quad 45 \mathrm{~s}: \quad 6.71 \pm 0.89 ; 90 \mathrm{~s}: 9.29 \pm 1.49 \mathrm{~min})$ were reached earlier following faster i.v. infusions. To further examine this effect, we analysed the effects of infusion rate on the time interval before cocaine and dopamine concentrations were greater than baseline concentrations by two standard deviations. This further confirmed that a 5-s infusion led to the fastest increases in extracellular concentrations of cocaine and dopamine (Fig. $4 \mathrm{e} ; F_{2},{ }_{12}=6.42$, $P=0.01 ; 5$ vs. $90 \mathrm{~s}: t_{6}=2.74, P=0.03 ; 45$ vs. $90 \mathrm{~s}: t_{6}=2.59$, $P=0.04$; Fig. 4 f; $F_{2,12}=4.31, P=0.04 ; 5$ vs. $90 \mathrm{~s}: t_{6}=2.54$, $P=0.04)$. In parallel, we observed the animals during testing and we noted that locomotor activity increased earlier following rapid (5 s) vs. more sustained (45-90 s) i.v. cocaine infusions.

In summary, at all cocaine i.v. infusion rates, we measured a significant increase in drug and dopamine concentrations in the DS. Increasing the rate of i.v. cocaine delivery between 90 and $5 \mathrm{~s}$ did not significantly influence peak concentrations of the drug or of dopamine. However, cocaine and dopamine concentrations reached peak levels earlier following more rapid infusions.

\section{Cocaine and dopamine concentrations are tightly coupled across time}

Data from representative rats show that, at all infusion rates, cocaine and dopamine concentrations were very closely linked across time (Figs 5a-c). Across all experimental rats and infusion rates, there was a significant positive correlation between extracellular cocaine and dopamine concentrations at each sampling time after drug infusion (Fig. 5d; $r^{2}=0.77, P<0.0001$ ). There was also a significant positive correlation between extracellular cocaine and dopamine concentrations at each infusion rate $\left(5 \mathrm{~s}, r^{2}=0.61, P=0.0006\right.$; $45 \mathrm{~s}, r^{2}=0.88, P<0.0001 ; 90 \mathrm{~s}, r^{2}=0.91, P<0.0001$, Data not shown). This correlation was stronger following a 90 -s infusion compared to a 5 -s infusion $(Z=-2.02, P=0.04$; no other comparisons were statistically significant). The linear relationship between cocaine and dopamine was observed up to 187-220 nM cocaine, the highest concentrations measured following i.v. infusion of the drug over 5-90 s, respectively.

\section{I.v. cocaine infusion does not significantly influence striatal levels of other neurochemicals}

In addition to dopamine, we also measured extracellular concentrations of 20 other neurochemicals in the striatum after cocaine infusion. These were acetylcholine, adenosine, aspartate, $\gamma$-aminobutyric acid, glucose, glutamate, glutamine, glycine, histamine, norepinephrine, phenylalanine, serine, serotonin, taurine, tyrosine and the metabolites 3,4-dihydroxyphenylacetic acid, homovanillic acid, 3methoxytyramine, 5-hydroxyindoleacetic acid and normetanephrine in the DS. There were no significant effects of cocaine or of the rate of infusion on the concentrations of any of these (see Figures S1-S3).

\section{Locomotor activity increases earlier when cocaine is infused over $5 \mathrm{~s}$}

I.v. infusion rate did not influence the locomotor response to saline (Saline; $F_{2,9}=0.21, P=0.81$ ). Thus, saline-induced locomotion was pooled across rates and this served as the control condition. At all infusion rates, cocaine increased locomotor activity relative to saline (Fig. $6 ; \quad F_{3,33}=6.80, P=0.001 ; 5 \mathrm{~s}$ vs. Saline: $F_{1,11}=11.43$, 

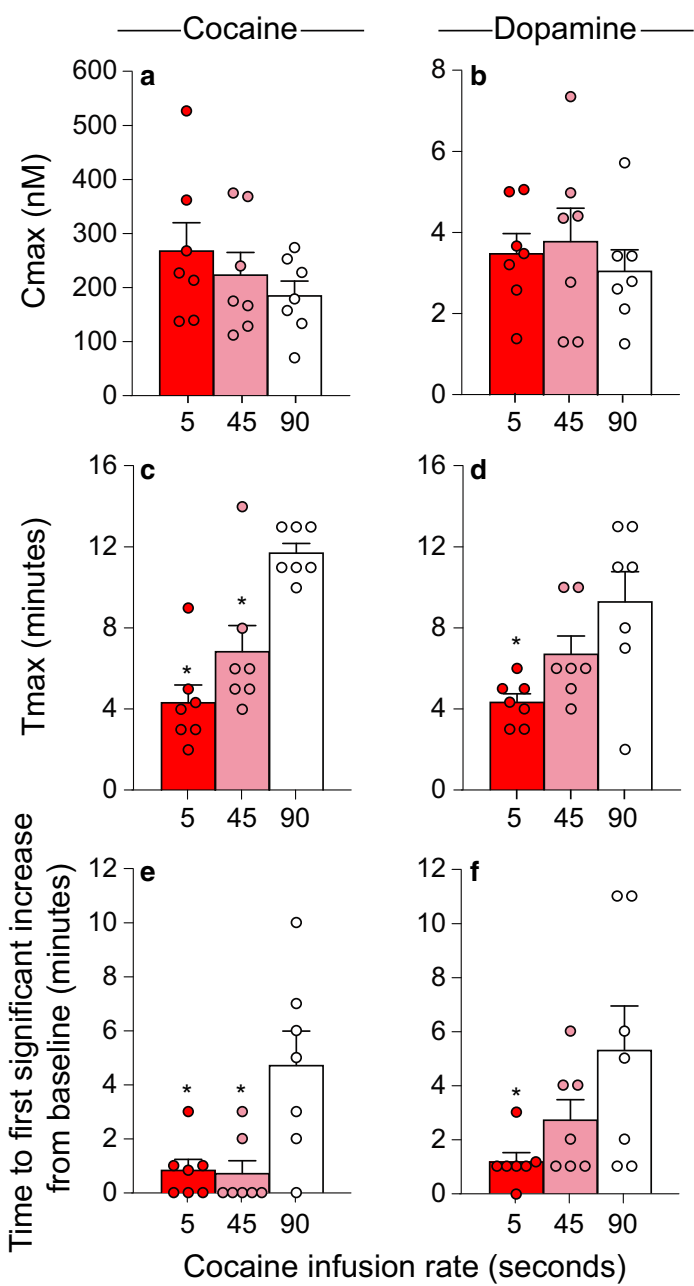

FIG. 4. Varying the rate of i.v. infusion between 5-90 s influences the rate of rise of cocaine and dopamine concentrations $\left(T_{\max }\right)$ in the dorsal striatum (DS) without producing large effects on maximum concentrations $\left(C_{\max }\right)$. Panels (a) and (b) show average $C_{\max }$ values for cocaine and dopamine, respectively, as a function of the rate of i.v. cocaine infusion. The time to reach peak concentrations $\left(T_{\max }\right)$ of cocaine (c) and dopamine (d) in the DS is shown as a function of the rate of i.v. cocaine delivery. Panels (e) and (f) show the time interval before cocaine and dopamine concentrations were significantly greater than baseline levels ( $>2$ standard deviations above baseline), as a function of the rate of i.v. cocaine delivery. All values are mean \pm SEM. $n=7$ rats/infusion rate. ${ }^{*} P<0.05$ compared to $90 \mathrm{~s}$. nM, nanomoles/litre. $s$, seconds.

$P=0.006 ; 45$ s vs. Saline: $F_{1,11}=16.24, P=0.002 ; 90$ s vs. Saline: $\left.F_{1,11}=27.74, P=0.0003\right)$, and all rates evoked a comparable increase in locomotion (One-way ANOVA on total locomotor counts over the $30 \mathrm{~min}$ after cocaine injection; $F_{1.10,12.13}=2.17, P=0.17$ ). However, infusion rate significantly influenced cocaine-induced locomotion across time (Infusion rate $\times$ Time interaction effect; $\left.F_{68,748}=1.47, P=0.01\right)$. To analyse this further, we compared locomotor activity in the first minute following cocaine injection. This showed that injecting cocaine i.v. over 5 vs. 90 s evokes greater locomotor activity in the first minute post-injection $\left(F_{1.57,17.24}=10.87\right.$, $P=0.002$; 5 vs. 90 s, $P=0.004)$.

\section{Discussion}

To our knowledge, the present experiment is the first to simultaneously measure brain concentrations of extracellular cocaine and dopamine in awake, freely moving rats, and to also assess the influence of the rate of i.v. cocaine infusion. We found that injecting cocaine i.v. between 5 and $90 \mathrm{~s}$ robustly increases cocaine and dopamine concentrations in the DS, without significantly altering peak concentrations of either analyte (see also Ferrario et al., 2008). However, drug and dopamine concentrations rose faster when cocaine was administered over $5 \mathrm{~s}$, such that peak concentrations were reached earlier. Previous work shows that compared to slower i.v. cocaine infusions $(25-100 \mathrm{~s})$, rapid infusions (5-16 s) promote the development of sensitization to both the psychomotor activating and incentive motivational effects of cocaine (Samaha et al., 2002, 2004; Liu et al., 2005; Minogianis et al., 2013; Bouayad-Gervais et al., 2014; Allain et al., 2017), lead to greater drug intake (Wakabayashi et al., 2010; Minogianis et al., 2013; Bouayad-Gervais et al., 2014), and increase the risk of cocaine-primed relapse following extended abstinence (Wakabayashi et al., 2010). Rapid cocaine delivery to the brain also preferentially engages mesocorticolimbic cells (Porrino, 1993; Samaha et al., 2004; Brown \& Kiyatkin, 2005; Ferrario et al., 2008). If rapid i.v. cocaine administration promotes these addiction-relevant effects by changing dopamine neurotransmission, our findings suggest that the critical factor is likely the time it takes to transition from low/baseline to high extracellular dopamine concentrations rather than any large differences in peak concentrations (Ferrario et al., 2008).

Our results confirm predictions derived from pharmacokinetic modelling. Samaha et al. (2002) used a pharmacokinetic model validated by Pan et al. (1991) and estimated that injecting cocaine i.v. over 5,50 or $100 \mathrm{~s}$ would not significantly influence peak brain concentrations of the drug, but would change the rate of rise of drug concentrations. Our findings confirm this to be the case. The temporal profile of brain cocaine concentrations we report also matches that in Samaha et al. (2002). However, Samaha et al. (2002) estimated higher peak cocaine values in the brain than measured here ( $\sim 4 \mu$ after $1 \mathrm{mg} / \mathrm{kg}$ i.v. cocaine compared to $0.2-0.26 \mu \mathrm{M}$ after $2 \mathrm{mg} / \mathrm{kg}$ i.v. cocaine here). Samaha et al. (2002) used a pharmacokinetic model that estimates whole brain concentrations corrected for probe recovery rate, while here we report uncorrected concentrations from dialysate samples. Uncorrected concentration values in dialysate samples would be lower. In accordance with this, in the present study, an in vitro test showed that peak concentrations of cocaine detected by the probes were 10-fold lower than the concentration in the prepared solution $(0.1-0.14 \mu \mathrm{M}$ were detected in a 1$\mu \mathrm{M}$ cocaine solution). This represents a $10 \%$ probe recovery at the $2 \mu \mathrm{L} / \mathrm{min}$ flow rate used here. As such, keeping in mind the $10 \%$ recovery rate from the microdialysis probe, the striatal cocaine and dopamine values we report can be used to select behaviourally relevant cocaine and dopamine concentrations in in vitro experiments (Nicolaysen et al., 1988). Indeed, the cocaine dose we used (2 mg/kg) also produced a robust increase in psychomotor activity (detailed below).

Variation in the rate of i.v. cocaine infusion significantly influenced the temporal dynamics of cocaine and dopamine levels in the DS. By sampling at 1-min intervals, we found that peak brain concentrations of cocaine were reached $4 \mathrm{~min}$ after a 5 -s infusion, 7 min after a 45 -s infusion and 12 min after a 90-s infusion. Similarly, Hurd et al. (1988), who sampled every $10 \mathrm{~min}$, found that following an 85-s i.v. cocaine infusion, peak drug concentrations in the striatum are seen within the first 10 -min sample. The cocaine $T_{\max }$ values we observed here after a 5- vs. 90-s i.v. infusion are also generally similar to those seen in rats following i.v. (1-2 min) and intranasal (15 $\mathrm{min}$ ) cocaine administration, respectively (Chow et al., 1999). This suggests that injecting cocaine i.v. over 5 vs. 

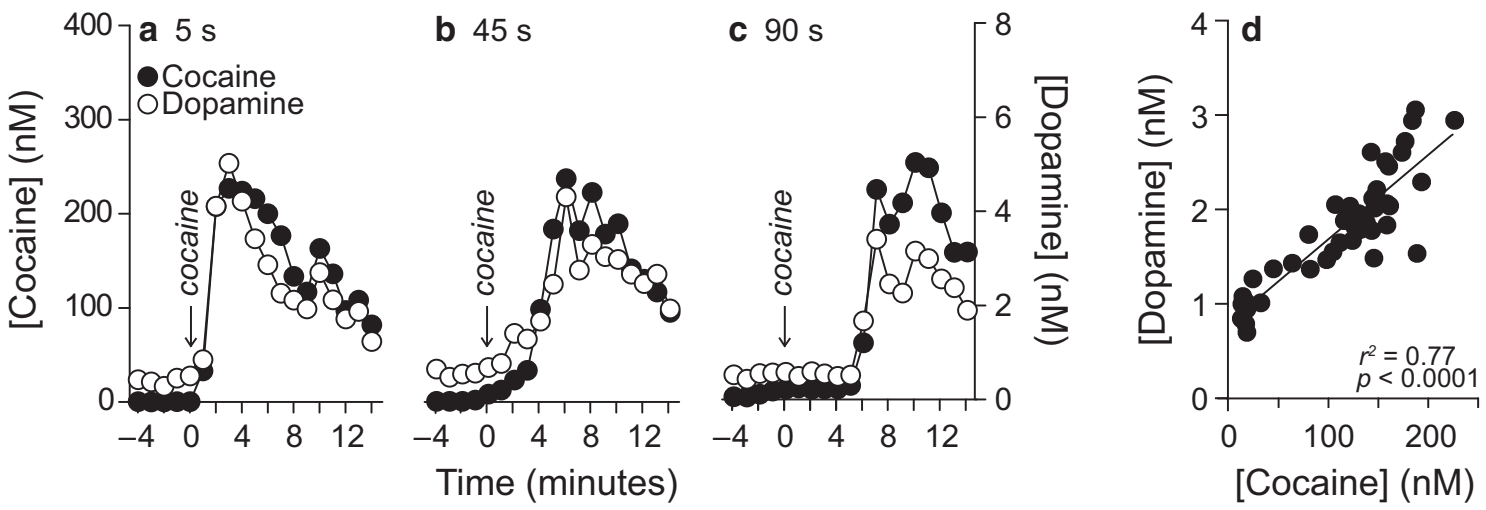

FIG. 5. Extracellular dopamine and cocaine concentrations in the dorsal striatum (DS) are linearly correlated. Panels (a-c) show extracellular concentrations of dopamine and cocaine over time from representative rats, for each i.v. infusion rate. Panel (d) shows a significant positive correlation between dopamine and cocaine concentrations in the DS, at each sampling time, across all rats and infusion rates. For this analysis, we used linear regression to model the relationship between dopamine concentrations and cocaine concentrations at each of the 15 post-cocaine samples. $n=7$ rats/infusion rate. nM, nanomoles/litre. s, seconds.

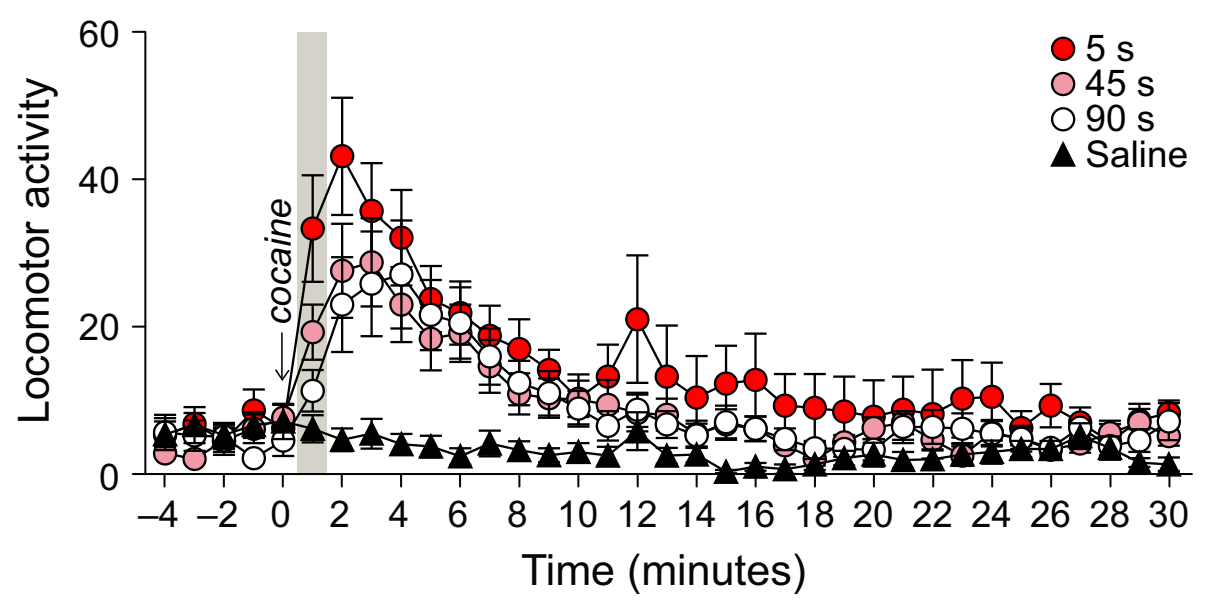

FIG. 6. The influence of the rate of i.v. cocaine infusion on locomotor activity. Locomotor activity (beam breaks per minute) as a function of i.v. drug infusion rate. Saline-induced locomotor activity is also shown for comparison. The shading highlights the first minute after cocaine, where locomotor activity was greater after a 5-s injection than after a 90-s injection. All values are mean \pm SEM. $n=12$ rats/infusion rate. s, seconds.

$90 \mathrm{~s}$ in rats can to some extent model the temporal kinetics of i.v. vs. intranasal cocaine. Our findings also agree with those of Ferrario et al. (2008) showing that infusing cocaine i.v. between 5 and $90 \mathrm{~s}$ does not produce large effects on peak dopamine concentrations in the striatum (or on area under the curve values for dopamine), but it produces significant differences in dopamine $T_{\max }$. Ferrario et al. (2008) also reported that dopamine concentrations start to rise 1$2 \mathrm{~min}$ after a 5-s i.v. cocaine infusion, and 3-3.5 min after a 100-s infusion. Similarly, here we found that dopamine concentrations begin to increase $1 \mathrm{~min}$ after a 5 -s cocaine infusion, and 5 min after a 90 -s infusion. We have previously used in vivo voltammetry techniques in urethane-anaesthetized rats and found that peak levels of dopamine reuptake inhibition occur within $1 \mathrm{~min}$ after a 5-s i.v. cocaine infusion (Samaha et al., 2004). This is much sooner than the time to reach peak brain concentrations of dopamine we observed here using awake, freely moving animals and in vivo microdialysis (4 min after a 5-s infusion). However, our findings agree with those of others using in vivo voltammetry techniques in awake, freely moving rats, and showing that peak dopamine inhibition does not occur until 6 min after a $12-15$ s i.v. cocaine infusion (Kiyatkin et al., 2000). The reasons for the discrepancy between these findings could involve the use of anaesthetized vs. awake animals. It is also possible that there is a non-linear relationship between the ability of an i.v. infusion of cocaine to occupy dopamine transporters and its ability to block the reuptake of dopamine, and thus increase dopamine overflow (Brodnik et al., 2017).

Brain cocaine and dopamine concentrations were tightly coupled across time, at all infusion rates. This agrees with previous studies where cocaine was given via the intraperitoneal or i.v. routes (Nicolaysen et al., 1988; Shou et al., 2006). Thus, once in the brain, cocaine quickly occupies dopamine transporters, producing rapid dopamine reuptake blockade and overflow into the extracellular space. The cocaine-induced increases in dopamine concentrations we measured here are likely largely due to blockade of the dopamine transporter, but cocaine could also be altering dopamine release (Venton et al., 2006; Mejias-Aponte et al., 2015). As this matter is resolved, the very close temporal relationship between brain cocaine and dopamine concentrations we observed suggests that the pharmacokinetic profile of one compound can be used as a proxy for the other.

In contrast with what we observed with dopamine, acute i.v. cocaine injections did not change the concentrations of other neurochemicals in the striatum. We tested only one (albeit relatively high) dose of cocaine. In addition, our rats received a total of three 
cocaine infusions. This might not be sufficient to reliably alter extracellular concentrations of some of the compounds we measured. For instance, several exposures to cocaine are generally needed to significantly increase striatal glutamate concentrations (Zhang et al., 2001). Interestingly, here and in prior work (Hurd \& Ungerstedt, 1989), cocaine did not significantly change dopamine metabolite concentrations (DOPAC, HVA and 3-MT), even though the drug robustly increased extracellular dopamine concentrations. This suggests that the relationship between dopamine release and metabolism is not simple. Cocaine might not significantly change dopamine metabolite concentrations in the DS because the drug potently blocks dopamine reuptake, thus preventing dopamine metabolism in the cell terminal (Hurd \& Ungerstedt, 1989). Although acute cocaine can significantly increase norepinephrine overflow in the ventral striatum (Reith et al. 1997), we found no effects on norepinephrine overflow in the DS. To our knowledge, this is the first report on how systemic cocaine administration influences norepinephrine overflow in the DS. The DS contains a limited density of scattered noradrenergic axons and very little norepinephrine (Fornai et al., 1996). We also saw no effect of i.v. cocaine on serotonin concentrations in the DS. This was surprising as cocaine has similar affinities for brain serotonin and dopamine transporters (Miller et al., 2001; Rothman et al., 2001). Others have reported that acute cocaine increases extracellular concentrations of serotonin in the dorsal (Bradberry et al., 1993) and ventral (Essman et al., 1994) striatum. The discrepancy between our findings and these reports could be due to the use of anaesthetized rats (Bradberry et al., 1993), the route of cocaine administration (Bradberry et al., 1993) and the striatal subregion sampled (Essman et al., 1994).

The rate of cocaine infusion also influenced the temporal dynamics of psychomotor activity. Although i.v. infusion rate did not significantly influence total levels of cocaine-induced locomotion, faster i.v. infusions evoked a greater locomotor response in the first minute after infusion. Thus, the rate of cocaine infusion influenced the temporal dynamics of both dopamine concentrations and druginduced psychomotor activity. However, the relationship between these two measures is not straightforward. First, at all infusion rates, cocaine-induced locomotion both peaked earlier and returned to baseline levels sooner than drug or dopamine concentrations (compare Figs 6 and 3). We measured cocaine/dopamine concentrations and cocaine-induced locomotor activity in different animals. However, others have taken the two measures in the same animals and also found that in previously drug-naive rats, cocaine-induced locomotion peaks earlier than cocaine-induced dopamine concentrations (Kalivas \& Duffy, 1990, but see Hemby et al., 1994). Other studies with methylphenidate (Gerasimov et al., 2000) or nicotine (Benwell \& Balfour, 1992) also show a similar effect. Combined, the present study and these prior reports have measured drug-induced dopamine overflow in both the dorsal and ventral striatum. Thus, it is possible that drug-induced dopamine accumulation outside of these brain regions also significantly contributes to the psychomotor response (Kalivas \& Duffy, 1990). It is also possible that cocaine increases dopamine concentrations in the synapse to induce psychomotor activity, without proportionate or immediate diffusion of dopamine outside of the synapse, to the microdialysis probe (Gonon, 1988; Kalivas \& Duffy, 1990). This would explain why cocaine-induced dopamine concentrations detected by the probe peak later in time compared to cocaine-induced locomotion.

There are elements to consider in interpreting our findings. First, we do not know how the rate of i.v. cocaine infusion influences cocaine/dopamine pharmacokinetics in extra-striatal brain regions. We would predict that the cocaine pharmacokinetics we measured in the DS likely reflect those in the rest of the brain. Indeed, cocaine is distributed uniformly in the brain following i.v. or intranasal administration (Reed \& Spiehler, 1985). A Positron Emission Tomography study in humans also suggests that drug pharmacokinetics in individual brain regions are very similar to those in whole brain (Berridge et al., 2010). Second, the neurobehavioural effects of cocaine that are relevant to addiction come about following chronic exposure to the drug. We do not know how our measurements would change with more extensive drug exposure. Of note, brain and blood concentrations of cocaine do not significantly change following repeated i.v. administration (Pan et al., 1991). However, i.v. cocaine-induced inhibition of dopamine reuptake can increase with repeated exposure (Brodnik et al., 2017). This being said, studying brain cocaine and dopamine pharmacokinetics after a single cocaine exposure is important. A single exposure to psychostimulant drugs like cocaine or d-amphetamine can produce effects that are relevant to the addiction process, in both laboratory rats and humans. These effects include psychomotor sensitization (Robinson et al., 1982; Lin-Chu et al., 1985; Strakowski \& Sax, 1998; Samaha et al., 2002) and changes in spine density on medium spiny neurons of the nucleus accumbens (Kolb et al., 2003). Finally, we only tested a single cocaine dose, but we would predict that, across a range of cocaine doses, varying the rate of i.v. drug infusion changes the rate of rise of drug concentrations in the brain.

In summary, we measured striatal concentrations of cocaine and dopamine, as well as cocaine-induced locomotion across a range of i.v. infusion rates that significantly influences brain and behaviour (Reviewed in Samaha \& Robinson, 2005; Allain et al., 2015). We found that increasing the rate of i.v. drug delivery increases the rate of rise of cocaine and dopamine concentrations in the DS, without producing large effects in peak concentrations. This was linked to a more immediate increase in locomotor activity following rapid vs. slower i.v. cocaine infusions. Thus, our results raise the possibility that differences in the rate of cocaine rise alone can determine outcome, perhaps by influencing the temporal dynamics of dopamine accumulation in the synapse, and the temporal pattern of dopamine receptor occupancy. In support of this, work in humans shows that smoked and intranasal cocaine can produce equivalent levels of dopamine transporter blockade, but smoked cocaine produces a stronger self-reported high (Volkow et al., 2000). Thus, we conclude that differences in the rate of rise of drug and dopamine levels in the brain might be an important issue in thinking about why drugs, formulations and routes of administration that achieve a rapid drug onset are the most addictive.

\section{Supporting Information}

Additional supporting information may be found online in the Supporting Information section at the end of the article:

Fig. S1. Cocaine had no significant effect on non-dopaminergic neurotransmitters in the dorsal striatum.

Fig. S2. Cocaine had no significant effect on neuromodulators in the dorsal striatum.

Fig. S3. Cocaine had no significant effect on neurotransmitter metabolites in the dorsal striatum.

\section{Acknowledgements}

This research was supported by grants from the Canadian Institutes of Health Research (Grant No. 157572) and the Canada Foundation for Innovation (Grant No. 24326) to ANS, as well as a discovery grant from the Natural 
Sciences and Engineering Research Council (NSERC) of Canada (Grant No. RGPIN-2016-06653) awarded to WGB. ANS holds a salary award from the Fonds de Recherche du Québec - Santé (Grant No. 28988). EAM holds a graduate fellowship from the Fonds de Recherche du Québec - Santé (Grant No. 29651). WMS holds a graduate fellowship from the Fonds de Recherche du Québec - Nature et Technologies. OSM was supported by the Michael J Fox Foundation for Parkinson's Disease Research (BioFind and Dyskinesia Challenge). RTK was supported by NIH R37 EB003320.

\section{Conflict of interest}

The authors declare no conflicts of interest.

\section{Data accessibility}

Raw data generated by these experiments will be stored on Figshare. Data and statistical analyses will be made available upon request.

\section{Author contributions}

ANS, EAM, WGB and WMS designed the study. EAM and WMS performed the in vivo microdialysis experiments. OSM and JTW analysed microdialysis samples with HPLC-MS/MS. EAM performed the psychomotor activity experiment. EAM, WMS, PS, OSM, JTW, RTK and ANS analysed the data and interpreted the findings. EAM and ANS drafted the manuscript. PS, RTK, WMS, OSM, JTW and WGB critically revised the manuscript. All authors critically reviewed content and approved final version for publication.

\section{Abbreviations}

aCSF, artificial cerebrospinal fluid; ANOVA, analysis of variance; $C_{\max }$, maximal concentration; DS, dorsal striatum; h, hours; i.v., intravenous; $\mathrm{NacC}$, nucleus accumbens core; $\mathrm{NacSh}$, nucleus accumbens shell; nM, nanomoles per litre; s, seconds; SEM, standard error of the mean; $T_{\max }$, time to reach maximal concentration; $\mu \mathrm{M}$, micromoles per litre.

\section{References}

Abreu, M.E., Bigelow, G.E., Fleisher, L. \& Walsh, S.L. (2001) Effect of intravenous injection speed on responses to cocaine and hydromorphone in humans. Psychopharmacology, 154, 76-84.

Allain, F., Minogianis, E.-A., Roberts, D.C. \& Samaha, A.-N. (2015) How fast and how often: the pharmacokinetics of drug use are decisive in addiction. Neurosci. Biobehav. Rev., 56, 166-179.

Allain, F., Roberts, D.C., Levesque, D. \& Samaha, A.N. (2017) Intermittent intake of rapid cocaine injections promotes robust psychomotor sensitization, increased incentive motivation for the drug and mGlu2/3 receptor dysregulation. Neuropharmacology, 117, 227-237.

Balster, R.L. \& Schuster, C.R. (1973) Fixed-interval schedule of cocaine reinforcement: effect of dose and infusion duration1. J. Exp. Anal. Behav., 20, 119-129.

Benwell, M.E. \& Balfour, D.J. (1992) The effects of acute and repeated nicotine treatment on nucleus accumbens dopamine and locomotor activity. $\mathrm{Br}$. J. Pharmacol., 105, 849-856.

Berridge, M.S., Apana, S.M., Nagano, K.K., Berridge, C.E., Leisure, G.P. \& Boswell, M.V. (2010) Smoking produces rapid rise of [11C]nicotine in human brain. Psychopharmacology, 209, 383-394.

Bouayad-Gervais, K., Minogianis, E.-A., Lévesque, D. \& Samaha, A.-N. (2014) The self-administration of rapidly delivered cocaine promotes increased motivation to take the drug: contributions of prior levels of operant responding and cocaine intake. Psychopharmacology, 231, 4241-4252.

Bradberry, C.W., Nobiletti, J.B., Elsworth, J.D., Murphy, B., Jatlow, P. \& Roth, R.H. (1993) Cocaine and cocaethylene: microdialysis comparison of brain drug levels and effects on dopamine and serotonin. J. Neurochem., 60, 1429-1435.

Brodnik, Z.D., Ferris, M.J., Jones, S.R. \& España, R.A. (2017) Reinforcing doses of intravenous cocaine produce only modest dopamine uptake inhibition. ACS Chem. Neurosci., 8, 281-289.

Brown, P.L. \& Kiyatkin, E.A. (2005) Brain temperature change and movement activation induced by intravenous cocaine delivered at various injection speeds in rats. Psychopharmacology, 181, 299-308.
Chow, H.H.S., Chen, Z. \& Matsuura, G.T. (1999) Direct transport of cocaine from the nasal cavity to the brain following intranasal cocaine administration in rats. J. Pharm. Sci., 88, 754-758.

Comer, S.D., Collins, E.D., MacArthur, R.B. \& Fischman, M.W. (1999) Comparison of intravenous and intranasal heroin self-administration by morphine-maintained humans. Psychopharmacology, 143, 327-338.

Dutta, S., Matsumoto, Y., Gothgen, N.U. \& Ebling, W.F. (1997) Concentration-EEG effect relationship of propofol in rats. J. Pharm. Sci., 86, $37-43$.

Essman, W.D., Singh, A. \& Lucki, I. (1994) Serotonergic properties of cocaine: effects on a 5-HT2 receptor-mediated behavior and on extracellular concentrations of serotonin and dopamine. Pharmacol. Biochem. Behav., 49, 107-113.

Everitt, B.J. \& Robbins, T.W. (2005) Neural systems of reinforcement for drug addiction: from actions to habits to compulsion. Nat. Neurosci., 8 , 1481-1489.

Ferrario, C., Shou, M., Samaha, A., Watson, C., Kennedy, R. \& Robinson, T. (2008) The rate of intravenous cocaine administration alters c-fos mRNA expression and the temporal dynamics of dopamine, but not glutamate, overflow in the striatum. Brain Res., 1209, 151-156.

Fischman, M. \& Schuster, C. (1984) Injection duration of cocaine in humans. Fed. Proc., 43, 570.

Fornai, F., Torracca, M.T., Bassi, L., D’Errigo, D.A., Scalori, V. \& Corsini, G.U. (1996) Norepinephrine loss selectively enhances chronic nigrostriatal dopamine depletion in mice and rats. Brain Res., 735, 349-353.

Gerasimov, M.R., Franceschi, M., Volkow, N.D., Gifford, A., Gatley, S.J., Marsteller, D., Molina, P.E. \& Dewey, S.L. (2000) Comparison between intraperitoneal and oral methylphenidate administration: a microdialysis and locomotor activity study. J. Pharmacol. Exp. Ther., 295, 51-57.

Gonon, F.G. (1988) Nonlinear relationship between impulse flow and dopamine released by rat midbrain dopaminergic neurons as studied by in vivo electrochemistry. Neuroscience, 24, 19-28.

Gossop, M., Griffiths, P., Powis, B. \& Strang, J. (1994) Cocaine: patterns of use, route of administration, and severity of dependence. Brit. J. Psychiat., 164, 660-664.

Hatsukami, D.K. \& Fischman, M.W. (1996) Crack cocaine and cocaine hydrochloride: are the differences myth or reality? JAMA, 276, 15801588.

Hemby, S., Jones, G., Hubert, G., Neill, D. \& Justice, J. (1994) Assessment of the relative contribution of peripheral and central components in cocaine place conditioning. Pharmacol. Biochem. Behav., 47, 973-979.

Henningfield, J.E. \& Keenan, R.M. (1993) Nicotine delivery kinetics and abuse liability. J. Consult. Clin. Psych., 61, 743-750.

Hurd, Y.L. \& Ungerstedt, U. (1989) Cocaine: an in vivo microdialysis evaluation of its acute action on dopamine transmission in rat striatum. Synapse, 3, 48-54.

Hurd, Y.L., Kehr, J. \& Ungerstedt, U. (1988) In vivo microdialysis as a technique to monitor drug transport: correlation of extracellular cocaine levels and dopamine overflow in the rat brain. J. Neurochem., 51, 1314-1316.

Javaid, J., Fischman, M., Schuster, C.R., Dekirmenjian, H. \& Davis, J. (1978) Cocaine plasma concentration: relation to physiological and subjective effects in humans. Science, 202, 227-228.

Jeffcoat, A.R., Perez-Reyes, M., Hill, J.M., Sadler, B.M. \& Cook, C.E. (1989) Cocaine disposition in humans after intravenous injection, nasal insufflation (snorting), or smoking. Drug Metab. Dispos., 17, 153-159.

Jones, R.T. (1984) The pharmacology of cocaine. NIDA Res. MG., 50, 34 53.

Jones, R.T. (1990) The pharmacology of cocaine smoking in humans. NIDA Res. MG., 99, 30-41.

Kalivas, P.W. \& Duffy, P. (1990) Effect of acute and daily cocaine treatment on extracellular dopamine in the nucleus accumbens. Synapse, 5, $48-58$.

Kiyatkin, E., Kiyatkin, D. \& Rebec, G. (2000) Phasic inhibition of dopamine uptake in nucleus accumbens induced by intravenous cocaine in freely behaving rats. Neuroscience, $\mathbf{9 8 ,}$ 729-741.

Kolb, B., Gorny, G., Li, Y., Samaha, A.-N. \& Robinson, T.E. (2003) Amphetamine or cocaine limits the ability of later experience to promote structural plasticity in the neocortex and nucleus accumbens. Proc. Natl. Acad. Sci. USA, 100, 10523-10528.

Larson, J. \& Lynch, G. (1986) Induction of synaptic potentiation in hippocampus by patterned stimulation involves two events. Science, 232, 985-988.

Lin-Chu, G., Robinson, T.E. \& Becker, J.B. (1985) Sensitization of rotational behavior produced by a single exposure to cocaine. Pharmacol. Biochem. Behav., 22, 901-903. 
Liu, Y., Roberts, D. \& Morgan, D. (2005) Sensitization of the reinforcing effects of self-administered cocaine in rats: effects of dose and intravenous injection speed. Eur. J. Neurosci., 22, 195-200.

Marsch, L.A., Bickel, W.K., Badger, G.J., Rathmell, J.P., Swedberg, M.D., Jonzon, B. \& Norsten-Höog, C. (2001) Effects of infusion rate of intravenously administered morphine on physiological, psychomotor, and selfreported measures in humans. J. Pharmacol. Exp. Ther., 299, 1056-1065.

Mejias-Aponte, C.A., Ye, C., Bonci, A., Kiyatkin, E.A. \& Morales, M. (2015) A subpopulation of neurochemically-identified ventral tegmental area dopamine neurons is excited by intravenous cocaine. J. Neurosci., 35, 1965-1978.

Miller, G.M., Yatin, S.M., De La Garza Ii, R., Goulet, M. \& Madras, B.K. (2001) Cloning of dopamine, norepinephrine and serotonin transporters from monkey brain: relevance to cocaine sensitivity. Mol. Brain Res., 87, 124-143.

Minogianis, E.-A., Lévesque, D. \& Samaha, A.-N. (2013) The speed of cocaine delivery determines the subsequent motivation to self-administer the drug. Neuropsychopharmacology, 38, 2644-2656.

Nayak, P., Misra, A. \& Mule, S. (1976) Physiological disposition and biotransformation of $(3 \mathrm{H})$ cocaine in acutely and chronically treated rats. $J$. Pharmacol. Exp. Ther., 196, 556-569.

Nicolaysen, L.C., Pan, H.-T. \& Justice Jr, J.B. (1988) Extracellular cocaine and dopamine concentrations are linearly related in rat striatum. Brain Res., 456, 317-323.

Pan, H.T., Menacherry, S. \& Justice, J. (1991) Differences in the pharmacokinetics of cocaine in naive and cocaine-experienced rats. J. Neurochem., 56, 1299-1306.

Paxinos, G. \& Watson, C. (1986). The Rat Brain in Stereotaxic Coordinates. Academic Press, San Diego, CA, p. 119.

Porrino, L.J. (1993) Functional consequences of acute cocaine treatment depend on route of administration. Psychopharmacology, 112, 343-351.

Reed, D. \& Spiehler, V.R. (1985) Brain concentrations of cocaine and benzoylecgonine in fatal cases. J. Forensic Sci., 30, 1003-1011.

Reith, M., Li, M.Y. \& Yan, Q.S. (1997) Extracellular dopamine, norepinephrine, and serotonin in the ventral tegmental area and nucleus accumbens of freely moving rats during intracerebral dialysis following systemic administration of cocaine and other uptake blockers. Psychopharmacology, 134, 309-317.

Resnick, R., Kestenbaum, R. \& Schwartz, L. (1977) Acute systemic effects of cocaine in man: a controlled study by intranasal and intravenous routes. Science, 195, 696-698.

Robinson, T.E., Becker, J.B. \& Presty, S.K. (1982) Long-term facilitation of amphetamine-induced rotational behavior and striatal dopamine release produced by a single exposure to amphetamine: sex differences. Brain Res., 253, 231-241.

Rothman, R.B., Baumann, M.H., Dersch, C.M., Romero, D.V., Rice, K.C., Carroll, F.I. \& Partilla, J.S. (2001) Amphetamine-type central nervous system stimulants release norepinephrine more potently than they release dopamine and serotonin. Synapse, 39, 32-41.

Samaha, A.-N. \& Robinson, T.E. (2005) Why does the rapid delivery of drugs to the brain promote addiction? Trends Pharmacol. Sci., 26, 82-87.
Samaha, A.-N., Li, Y. \& Robinson, T.E. (2002) The rate of intravenous cocaine administration determines susceptibility to sensitization. J. Neurosci., 22, 3244-3250.

Samaha, A.-N., Mallet, N., Ferguson, S.M., Gonon, F. \& Robinson, T.E. (2004) The rate of cocaine administration alters gene regulation and behavioral plasticity: implications for addiction. J. Neurosci., 24, 63626370

Shideman, F., Winters, W.D., Peterson, R.C., Wilner, W.K. \& Gould, T.C. (1953) The distribution and in vivo rate of metabolism of thiopental. J. Pharmacol. Exp. Ther., 107, 368-378.

Shou, M., Ferrario, C.R., Schultz, K.N., Robinson, T.E. \& Kennedy, R.T. (2006) Monitoring dopamine in vivo by microdialysis sampling and online CE-laser-induced fluorescence. Anal. Chem., 78, 6717-6725.

Song, P., Mabrouk, O.S., Hershey, N.D. \& Kennedy, R.T. (2012) In vivo neurochemical monitoring using benzoyl chloride derivatization and liquid chromatography - mass spectrometry. Anal. Chem., 84, 412-419.

Strakowski, S.M. \& Sax, K.W. (1998) Progressive behavioral response to repeated d-amphetamine challenge: further evidence for sensitization in humans. Biol. Psychiat., 44, 1171-1177.

Venton, B.J., Seipel, A.T., Phillips, P.E., Wetsel, W.C., Gitler, D., Greengard, P., Augustine, G.J. \& Wightman, R.M. (2006) Cocaine increases dopamine release by mobilization of a synapsin-dependent reserve pool. $J$. Neurosci., 26, 3206-3209.

Volkow, N.D., Wang, G.J., Fischman, M.W., Foltin, R., Fowler, J.S., Franceschi, D., Franceschi, M., Logan, J. et al. (2000) Effects of route of administration on cocaine induced dopamine transporter blockade in the human brain. Life Sci., 67, 1507-1515.

Wakabayashi, K.T., Weiss, M.J., Pickup, K.N. \& Robinson, T.E. (2010) Rats markedly escalate their intake and show a persistent susceptibility to reinstatement only when cocaine is injected rapidly. J. Neurosci., 30, 11346-11355.

Weiss, R. D., Mirin, S. M. \& Bartel, R. L. (1993) Cocaine. American Psychiatric Assoc Pub., Arlington, VA, USA.

Wieland, S., Schindler, S., Huber, C., Kohr, G., Oswald, M.J. \& Kelsch, W. (2015) Phasic dopamine modifies sensory-driven output of striatal neurons through synaptic plasticity. J. Neurosci., 35, 9946-9956.

Wong, J.-M.T., Malec, P.A., Mabrouk, O.S., Ro, J., Dus, M. \& Kennedy, R.T. (2016) Benzoyl chloride derivatization with liquid chromatographymass spectrometry for targeted metabolomics of neurochemicals in biological samples. J. Chromatogr. A, 1446, 78-90.

Woolverton, W.L. \& Wang, Z. (2004) Relationship between injection duration, transporter occupancy and reinforcing strength of cocaine. Eur. J. Pharmacol., 486, 251-257.

Zernig, G., Giacomuzzi, S., Riemer, Y., Wakonigg, G., Sturm, K. \& Saria, A. (2003) Intravenous drug injection habits: drug users' self-reports versus researchers' perception. Pharmacology, 68, 49-56.

Zhang, Y., Loonam, T.M., Noailles, P.A. \& Angulo, J.A. (2001) Comparison of cocaine-and methamphetamine-evoked dopamine and glutamate overflow in somatodendritic and terminal field regions of the rat brain during acute, chronic, and early withdrawal conditions. Ann. N. Y. Acad. Sci., 937, 93-120. 